\title{
An Engineering Approach to Develop Business Networks
}

\author{
Rainer Alt, Christian Reichmayr, Thomas Puschmann, Florian Leser and \\ Hubert Oesterle \\ Institute of Information Management, University of St. Gallen \\ Mueller-Friedberg-Strasse 8, CH-9000 St. Gallen, Switzerland \\ Phone: (+41) 712242420 / Facsimile: (+41) 712242777
}

\{Firstname.Lastname\}@unisg.ch

Abstract: In order to attain Business Networking goals, such as the simple and fast exchange of transactions, increased customer care or reduced inventories, business partners have to be convinced about new ideas, new business processes among them and new (information) systems. For implementation to be successful, a variety of decisions will have to be taken concerning strategy, process and systems. Business Networking projects require a methodical approach completely different from that of traditional ERP implementations. The proposed method therefore guides managers in designing and implementing cooperation-intensive business networks. It covers aspects from strategy to implementation and follows the principles of method engineering. The 'Woodbridge'-Cases illustrates the method in practice.

\section{CHALLENGES OF IMPLEMENTING BUSINESS NETWORKS}

\subsection{Questions in Implementing Business Networks}

Following Kalakota/Robinson [1] companies are implementing eBusiness strategies in three areas: electronic commerce (sales and procurement), supply chain management (logistics) and customer relationship management (marketing and after sales). In order to characterise the development of these strategies for the B2B sector, the concept of Business Networking has been proposed [2]. Business Networking focuses in the first place on projects between business partners with a high co-operation intensity. Short-term, spot transactions are neglected in the following since they do not prevail in the B2B sector. 
Thus, the implementation of business networks will focus on co-operative structures, which have been described as hybrids between markets and hierarchies in the organisational literature [3], [4]. Generally, we refer to long-term relationships between at least two key suppliers and/or customers who conduct transactions with medium frequency and information breadth ${ }^{30}$. Our experience in several projects which aimed at shaping interaction among business partners, an area we refer to as Business Networking proposed [2], yielded that a variety of critical questions have to be answered:

- What are the potentials of co-operation and in which area will Business Networking yield the most benefits? What are possible co-operation scenarios, how can they be specified and evaluated?

- In order to reach Business Networking goals, such as improved customer care or reduced inventories, how can business partners get convinced, business processes among the partners agreed upon, and the strategic and process scenario translated into enabling IT applications?

- How to evaluate applications that can be integrated into existing system landscapes? What are the implications of the networking solution for the overall application and service architecture?

- What is a proven sequence for proceeding in a Business Networking project? What are the major steps and what are suitable techniques for ensuring quick and successful implementation?

\subsection{Existing Approaches and Requirements}

Methods are proven to helpful address these issues systematically, to take advantage of the experience gained in other projects, and to ensure the proper documentation of project activities. In the first place, a method for Business Networking has to take into account the specifics of inter-business relationships. The main areas are all aspects associated with co-operation, the extended supply chain and new (electronic) services. Existing methods emerged primarily from the three areas shown in Table 1: co-operation management, process (re-)design, and implementation of Business Networking systems.

However, these methods show shortcomings in three respects:

- They focus on a specific level of the Business Engineering model, i.e. they emphasise either the strategy, process or system level. They do not provide guidance from the co-operation strategy through to the implementation of a Business Networking system. For example, the methods for co-operation management offer valuable insights into setting up and managing co-operations,

30 The breadth of information describes the variety of exchanged information, e.g. not only transaction information, such as price, volume, article description, but also planning data and the like. 
but do not address the selection, configuration, and implementation of systems supporting these relationships.

- They frequently have only a low level of formalisation. Systematic methods require a meta model, a procedure model, techniques, a role model, as well as result documents. Many methods, especially in strategy development and cooperation management, include only a procedure model and some techniques. Structured documentation of the result is often lacking, despite the fact that these documents form an important input for system implementation.

- They do not provide support for networking processes. The networking processes consist of electronic commerce (EC), supply chain management (SCM), customer relationship management (CRM) and the like. Existing methods are either generalised (e.g. BPR methods) or focus on designing particular networking processes (e.g. supply chain methods)

The goal is to present an initial outline of a method for Business Networking. The following requirements can be noted:

- The method should provide support for co-operation-intensive projects in the design, measurement, and implementation of collaboration processes.

- It should include new business models, potentials of electronic processes (e.g. EC, SCM), as well as the implications of using new Information Systems (IS).

- The method should take 'eService-provider' into account - a new form of organisation that (1) support co-operation between companies and/or consumers, (2) are largely electronic, i.e. with no manual intervention, (3) are accessible via computers or smart appliances, (4) can be used individually or as a package, (5) are highly standardized, and (6) are charged according to use [5].

- It should include standardisation efforts - the concept of the 'Business Bus'. It describes the totality of technical, applications and business standards on which software solutions, electronic services, etc. are based. These include EDIFACT, cXML, RosettaNet, OAGIS (Open Application Group Integration Specification) and OAMAS (Open Applications Group Middleware API), de facto standards for business objects such as those in the SAP environment (incl. the BAPIs as methods) or those of Microsoft's BizTalk, process standards like CPFR, and finally "laws" for Business Networking, e.g. generally valid rules for dealing with delays in delivery as now agreed in some cases between the participants in a supply chain [2], [6].

- It should include knowledge of existing methods and follow the design principles of method engineering [7]. 


\begin{tabular}{|c|c|c|}
\hline Strengths & Weaknesses & Examples \\
\hline \multicolumn{3}{|c|}{ Methods for Co-operation Management } \\
\hline $\begin{array}{l}\text { - Propose examples of models } \\
\text { for establishing and managing } \\
\text { co-operations } \\
\text { - Often include political and } \\
\text { social aspects }\end{array}$ & $\begin{array}{l}\text { - Lack advice on specific types of } \\
\text { co-operations and the role of IT } \\
\text { - Inadequate specificity concerning } \\
\text { business processes }\end{array}$ & $\begin{array}{l}{[8],[9],} \\
{[10],[11],} \\
{[12]}\end{array}$ \\
\hline \multicolumn{3}{|c|}{$\begin{array}{l}\text { Methods for Business Process (Re-)Design } \\
\end{array}$} \\
\hline $\begin{array}{l}\text { - Generalised and applicable to a } \\
\text { variety of industries } \\
\text { - Methods for supply chain } \\
\text { management (SCM) include } \\
\text { specific supply chain knowledge }\end{array}$ & $\begin{array}{l}\text { - Inadequate extended supply chain } \\
\text { focus and know-ledge of co-oper- } \\
\text { ations } \\
\text { - SCM methods neglect other } \\
\text { processes, e.g. customer relation- } \\
\text { ship process }\end{array}$ & $\begin{array}{l}{[13], \text { see }} \\
\text { overview } \\
\text { in }[14] \\
{[15],[16]}\end{array}$ \\
\hline \multicolumn{3}{|l|}{ Method for IS Implementation } \\
\hline $\begin{array}{l}\text { - Include vital specifics for } \\
\text { imple-menting Business } \\
\text { Networking Systems (e.g. SCM-, } \\
\text { EC-systems) }\end{array}$ & $\begin{array}{l}\text { - Methods are vendor and/or tool- } \\
\text { specific and are weak at the } \\
\text { strategy and process levels }\end{array}$ & $\begin{array}{l}{[17],[18],} \\
{[19],[20]}\end{array}$ \\
\hline
\end{tabular}

Table 1. Overview of Existing Methods in Business Networking

\subsection{Benefits of an Engineering Approach}

Method engineering is an approach developed by Gutzwiller/Heym [7], [21] to ensure the systematic development of methods. It has been used in the definition of various methods which are being used successfully in practice. Methods based on method engineering principles consist of five building blocks (see Figure 1):

- The procedure model contains the recommended sequence of all top-level activities. For example, a method for business process redesign may start with a preliminary analysis, continue with macro-design and finish with micro-design [22]

- Techniques describe how one or more results can be achieved. For example, a technique to measure supply chain performance includes the steps that have to be undertaken as well as various metrics, and provides hints on how to complete result documents. Tools, such as the ARIS Toolset [23], may support the application of techniques.

- Result documents are produced for the documentation of results and represent an important input for the specification of IT requirements. A result document for analysing as-is processes, for example, would be a process architecture. 
- Roles describe who is participating in a project at a certain stage. These are determined by the decisions which have to be taken and the knowledge required to complete the result documents.

- The meta model contains the main objects of design and the relationships between these objects. For example, a method for business process redesign would specify that processes produce outputs and consist of activities.

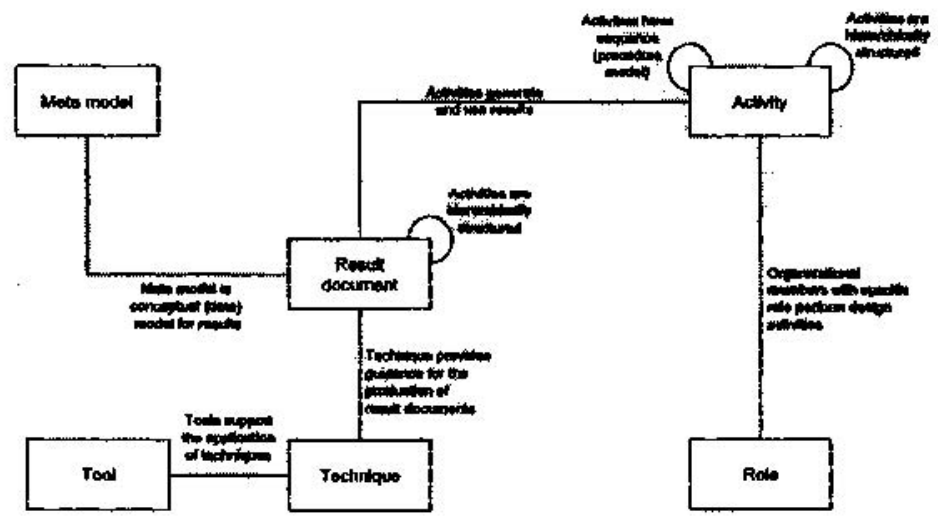

Figure 1. Elements of Method Engineering [7]

Besides helping to structure a project, methods are used to facilitate training and (self-)learning. In providing a common language they improve communication between people with heterogeneous backgrounds. Another advantage is that formalisation enables knowledge transfer, i.e. example result documents elaborated in one project can be used in another similar project. Experience has shown that these benefits are apt to lead to improvements in terms of hard (time, cost, quality) and soft (flexibility and knowledge) factors.

\section{TOWARDS A METHOD FOR BUSINESS NETWORKING}

In the following chapter, the structure of a method will be described which provides techniques that are applicable to all Business Networking strategies. The key features of the method are:

- the consistent usage of aspects relevant to co-operation at the strategy, process and IS level,

- the usage of method engineering which comprises a meta model, a role model, a procedure model and techniques plus various result documents, and 
- the representation of project experiences gained out of eBusiness and SCMprojects from 8 partner companies - Bayer AG, Robert Bosch GmbH, Deutsche Telekom AG, ETA SA (The Swatch Group), Hiserv GmbH, Hoffman-La Roche, Riverwood Int., and SAP AG.

\subsection{Design Areas of a Method for Business Networking}

The advantage of the Business Networking method is that it can start from existing and established approaches in business engineering. As shown in the left columns of Figure 2, business engineering "structures the organisation, data and function dimensions at the business strategy, process and information systems levels." [24]. The method for Business Networking proposes three co-operationspecific enhancements:

- Metrics. Besides well-known process metrics, peculiarities of quality, time, cost, and flexibility, the method also includes measurements for collaboration processes. These include the efficiency of setting up relationships with a new Organisation Unit (OU), the implementation of an EDI link to a new OU, and the like.

- Co-operation management. Although Business Networking is IT-enabled, Business Networking projects are not primarily technical projects and require substantial co-operation management skills. This includes selecting and convincing business partners, generating trust, defining win-win situations and co-operation contracts, conflict management, initiating pilot projects, setting up project teams, co-operation controlling procedures etc.

- Networking. Business Networking builds on a new business model. On the strategy level this includes new co-operation models, on the process level new forms of electronic co-ordination (e.g. multi-vendor product catalogues, supply chain scenarios), and on the systems level the use of eServices-providers and the design of the business bus.

The method's systematic approach involves successively elaborating and refining the content of the three dimensions. In the case of co-operation management, for example, the structure of the initial co-operation concept is retained when drawing up the co-operation contract - additional details are merely added. The co-operation contract in turn serves as the basis for co-operation controlling. In the same way, initial assessments of networkability are successively refined into concrete and quantitative indicators. 


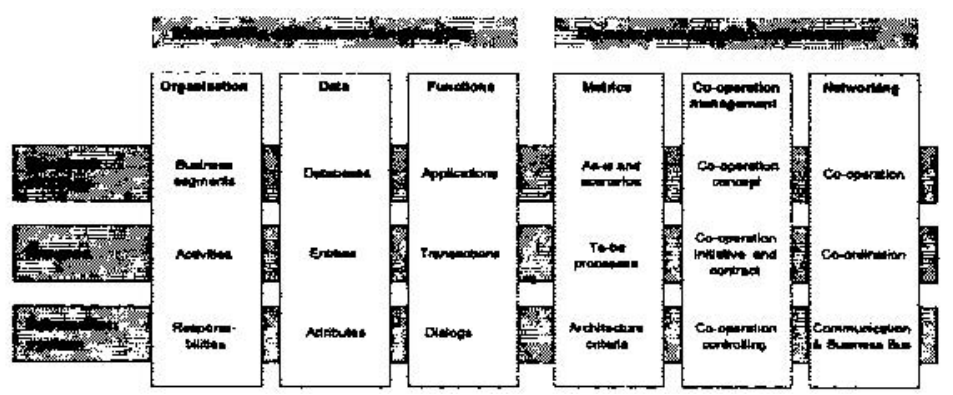

Figure2. Dimensions of Business Engineering and Co-operation-specific Enhancements

\subsection{Meta Model}

According to Brenner [25], a meta model is the conceptual data model of the results of a method and represents the constituent parts of the major design results of a method. Its purpose is to ensure consistency, providing a rapid overview of description and design areas and the terminology employed. The terms and their interrelationships are explained for each level (strategy, process, IS). Figure 3 shows the meta model at the strategy level with its entities and relationships. The gray scaled entities reflect the relationships to the process layer below.

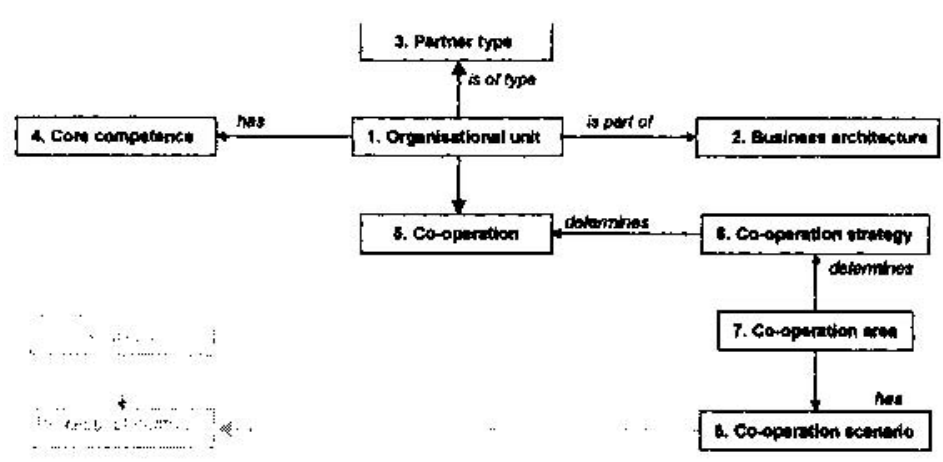

Figure3. Meta Model at Strategy Level

\subsection{Role Model}

The assignment of activities to ultimate units of responsibility is referred to as the role model. Roles are assumed by a business unit or individual employees, and involve tasks, competencies and responsibilities. The role model starts off by 
distinguishing the familiar roles of the people concerned: moderator, decisionmaker, responsible and supporter.

In addition to inwardly oriented BPR methods, co-operation projects require a role model which includes the roles of the co-operation partners. The method assumes that an initiator has a co-operation idea and successively concretises it. The first step takes place in the initiator's own company with an assessment of the cooperation idea (or vision), along with its scope, benefits and consequences. The decision whether to go ahead with a concrete co-operation project in co-operation with one or more pilot partners is then made on the basis of this assessment. The experience systematically collected from the pilot partner project is the prerequisite for winning several partners and/or for a roll-out.

\section{$2.4 \quad$ Procedure Model}

The Business Networking method assumes that co-operations not only have common characteristics but are also similar in their implementation. This procedure model was obtained in several partner projects and distinguishes the four top-level activities 'analyse, design, plan/implement' (see Figure 4):

- Analysis of co-operation potentials. First, an analysis is undertaken to determine the area(s) with the highest returns for Business Networking. Often, a quick preliminary study of 2-3 weeks is conducted for this purpose. The result of this phase is a co-operation concept which is presented to top management.

- Design and evaluation of scenarios. Based on a co-operation concept, the specific design alternatives are developed and evaluated. This phase is performed jointly with the co-operation partner and leads to a co-operation contract.

- Planning and implementation of pilot projects. Based on the co-operation contract, individual projects are carried out, e.g. process reengineering, EC or Advanced Planning System (APS) implementation. This phase links with the implementation methods of system vendors (e.g. SAP's ASAP).

- Continuation. Depending on the success of the pilot projects (and other criteria) it will be decided how the pilot solution is to be continued. Possible decisions are (1) roll out the solution to other OUs, (2) discontinue the pilot, and/or (3) pursue other co-operation projects. 


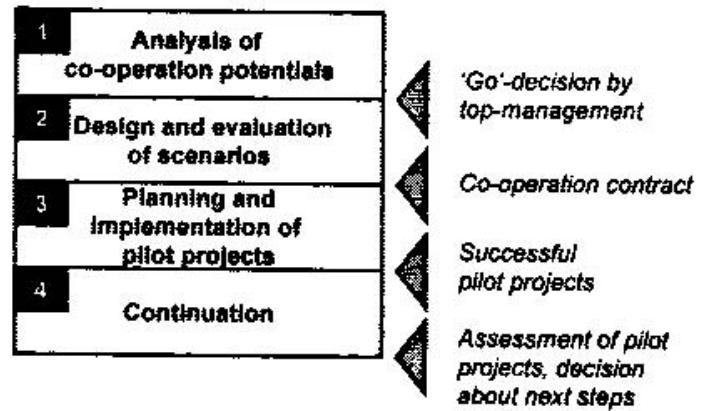

Figure4. Procedure Model of the Business Networking Method

\section{$2.5 \quad$ Techniques}

Procedure models define the temporal, logical sequence of steps in a problemsolving process [26]. The goals and results of each of the four phases of the Business Networking method are achieved by means of techniques which consist of a detailed procedure and result documents. The 11 techniques in total (see Figure 5) are explained below.

\begin{tabular}{|c|c|}
\hline \multirow{4}{*}{ 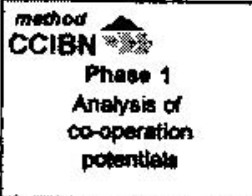 } & \$.1 Selection of co-operation area and project scope \\
\hline & 1.2 As-is process and application architecture \\
\hline & 1.3 Co-operation scenarios and metrics \\
\hline & 1.4 Co-operation concept \\
\hline \multirow{4}{*}{ Desion wow evatumition } & 2.1 Solection pllot partners \\
\hline & 2.2 Process ansalysts \\
\hline & 2.3 Design of application archllecture \\
\hline & 2.4 Conoporation intisatve \\
\hline \multirow{2}{*}{ 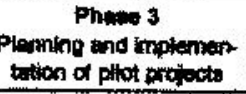 } & 3.1 Management of projoct portfolio \\
\hline & (internal project) \\
\hline \multirow{2}{*}{$\begin{array}{l}\text { Phanes of } \\
\text { Corthusidion }\end{array}$} & 4.1 Operational co-operation managemert \\
\hline & 4.2 Continustion \\
\hline
\end{tabular}

Figure5. Phases and Techniques of the Business Networking Method

\section{Phase 1: Analysis of co-operation potentials}

1.1 Selection of co-operation area and project scope. The areas in which cooperation is to take place are specified. The starting points are the co-operation goals and the co-operation road map which shows possible areas of co-operation. A performance analysis is carried out for assessment purposes, and the project initiator determines the relevant dimensions of the project and the composition of the project team. 
1.2 As-is process and application architecture. The as-is business, process and application network is modelled, taking into account the defined project scope. As-is analysis is the prerequisite for the design and implementation of optimised structures and processes.

1.3 Goals, potentials and architecture of the to-be process network. Collaboration scenarios, consisting of the business, process and IS architecture, are developed and evaluated according to the extent to which they meet the goals.

1.4 Co-operation concept. The main result document is the co-operation concept which is presented to the potential pilot partners at the beginning of the second phase (technique 2.1) and corresponds to a letter of intent. In order to achieve this result, the project initiator defines partner profiles, draws up a rough assessment of benefit categories (win-win situation) and selects the preferred type of partner.

\section{Phase 2: Design and evaluation of scenarios}

2.1 Pilot partner selection. The initiator selects the partners for the pilot project. The objective is to identify partners who have an interest in a quick win. The technique also includes team-building activities.

2.2 Process analysis. The focus is on defining the to-be process architecture. This involves selecting the strategic alignment and the basic processes. The objective is to develop the best suited process scenarios for which a standard software application already exists; i.e. the idea is not to develop a 'best case scenario' but one which can best be depicted in applications.

2.3 Design of IS architecture. The definitive choice of applications and eServices is made for the best suited application / eService scenario. The scenario is analysed to identify any shortcomings with regard to the processes modelled. This is followed by an analysis to determine how these gaps can be filled in terms of IS.

2.4 Co-operation initiative. This technique completes the co-operation contract in respect of common goals, obligations and resource deployment. The objective is to bring together the results obtained prior to implementation and, in particular, to review cost and benefit elements.

\section{Phase 3: Planning and implementation of pilot projects}

1.1 Management of the project portfolio. The inter-organisational activities required to achieve goals in respect of deadlines, costs and target fulfilment levels have to be co-ordinated. The methodological support for project realisation is not part of the Business Networking method; this is where the specific approaches of the project initiator, the pilot partners and the software manufacturer (e.g. ASAP for APO) come in.

(Execution of internal partner projects). Executes defined projects and monitors the delivery of results. It is not an integral element of the Business Networking method. 


\section{Phase 4: Continuation}

4.1 Establish operational co-operation management. The objective is to ensure that the co-operation runs smoothly and that the co-operation goals are actually fulfilled.

4.2 Continuation decision. A final review of the pilot project is performed and the success of the project communicated to the decision-makers. In addition, a 'business case' is drawn up to gain (roll out) partners and the success of the co-operation is marketed at the inter-organisational level. Finally, a decision is made on how to proceed, i.e. roll-out to other partners or follow on with a new co-operation project.

Although the method proposes an ideal sequence of activities, we are aware that certain projects require modifications. For this reason, each technique contains a clear description of the required inputs. This permits lower starting points, parallel activities, cycles and the like. In order to provide some insight into the individual phases and techniques a reference case will be described.

\section{REFERENCE CASE WOODBRIDGE, INT.}

The Woodbridge case that focuses on SCM-issues is fictitious and was developed in order to provide a general and neutral example to explain the use of the Business Networking method.

Woodbridge, Int. located in Seattle, Washington, is a long-established, international manufacturer of cardboard, aluminium and plastic packaging materials. The main customer in the USA is Walters Best in Richmond, Kentucky. Walters Best produces different types of pasta that are packaged with plastics from Woodbridge. Walters Best sells the pasta to its end-customers, i.e. supermarkets, wholesalers, etc. Woodbridge has its own car pool to deliver the materials to Walters Best distribution center.

\subsection{Phase 1: Analysis of Co-operation Potentials}

Over the last two years Woodbridge ran into financial difficulties for the first time. The reasons for this, as shown by internal analyses, were a new competitive situation, rising costs and quality demands. Management's first reaction was to perform various analyses, i.e. potentials and risks, stakeholder, as-is customer, market and portfolio analyses, etc. It was then decided to define new co-operation concepts, open up new markets in South America and increase the level of customer service. 


\subsubsection{Selection of Co-operation Area and Project Scope}

In order to improve external relationships it was decided to improve forecasting capabilities. In the past, it was not possible to exchange future demand figures electronically with business partners and no advanced planning system was in place to calculate different production plans. Customer demand was exchanged by telephone on a monthly basis only. Problems arising from this were:

- poor production capacity utilisation,

- high inventory stock levels at Woodbridge and Walters Best,

- no flexible reaction to changing demands, i.e. special offers, postponements, etc.

The results of all analyses revealed weaknesses in logistics and warehousing.

\subsubsection{As-is Process and IS Architecture}

The as-is situations of the following three result documents were established: business architecture, process architecture and IS architecture, The as-is business architecture shows a geographic overview of all linked business units, i.e. warehouses, plants, distribution centers, wholesalers, and, of course, end-customers (see Figure 6).
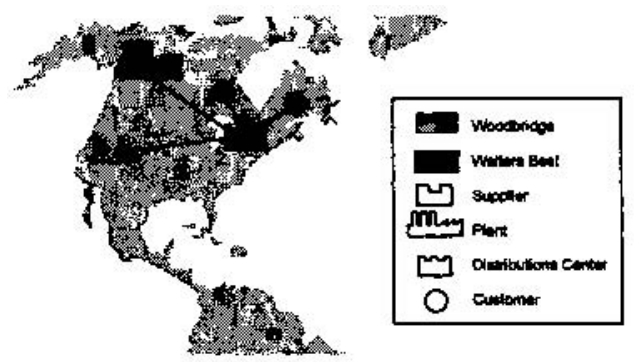

Figure6. As-Is Business Architecture

The process architecture consists of a macro and a micro level similar to established BPR methods [24]. The as-is process architecture describes all flows of information, goods and funds that are exchanged between business units (see Figure 7). The as-is process architecture at a more detailed (micro) level describes the main processes of the business units and their inputs and outputs within an activity chain diagram (see Figure 8). 


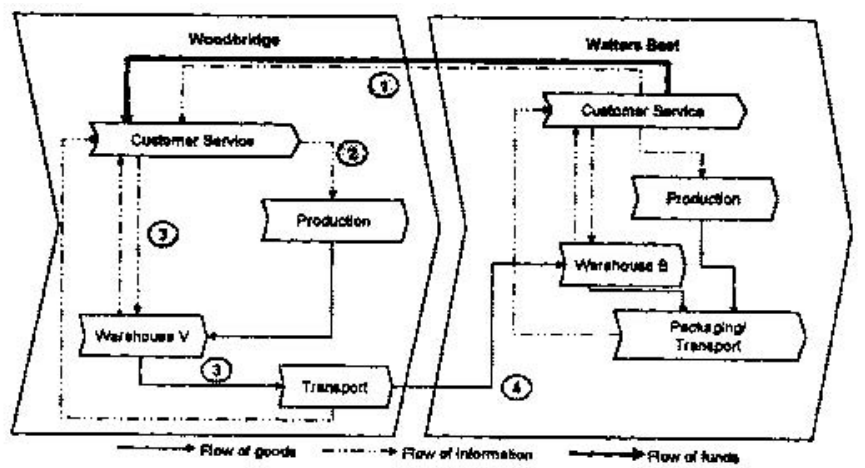

Figure 7. As-Is Process Architecture - Macro

At the beginning of the project the customer service from Walters Best ordered plastic materials from the Woodbridge customer service by telephone (1).

Woodbridge produced an account of these orders along with past trends (2), and delivered plastics from warehouse $\mathrm{V}$ to warehouse B ( $3 \& 4)$.

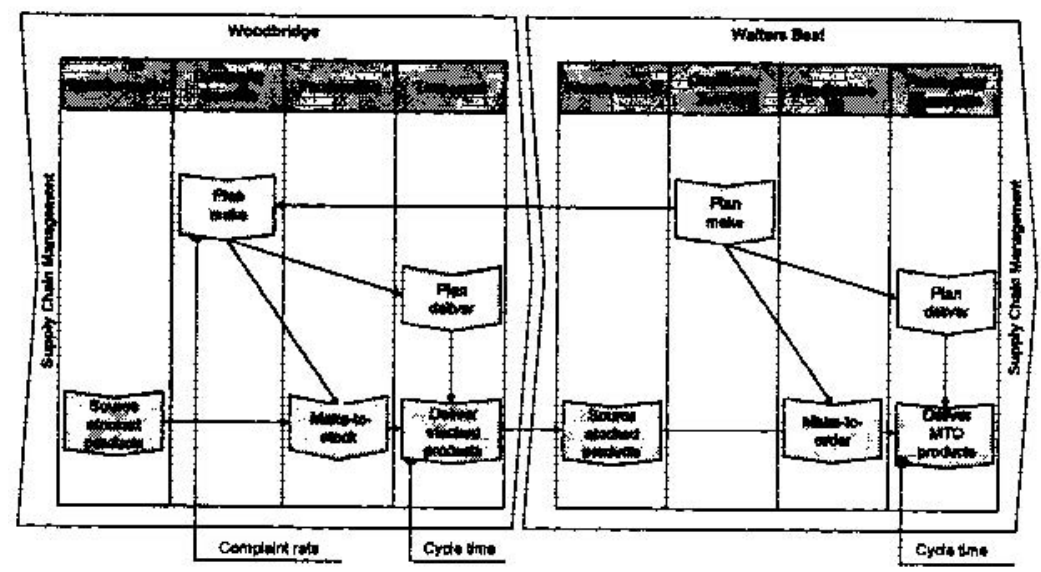

Figure 8. As-Is Process Architecture - Micro

As indicated in Figure 7 and Figure 8, there was neither an integrated planning function for the complete supply chain and future demands, nor an EC-solution to facilitate data exchange. Both enterprises only used ERP systems to plan their internal production (plan make), delivery (plan deliver), etc. (see Figure 9). 


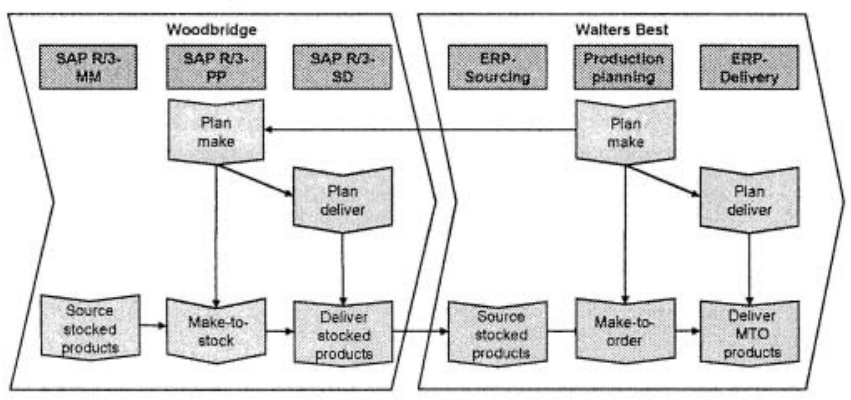

Figure 9. As-Is IS Architecture

\subsubsection{Goals, Potentials and Architecture of the to-be Process Network}

For the purpose of developing efficient collaboration scenarios, Woodbridge decided to consider benchmarking databases and best practices in the sector, such as Riverwood International. As a result, a Vendor Managed Inventory (VMI) ${ }^{31}$ scenario was established to solve the problems in production and warehousing. An eService scenario was developed to solve the problems in shipment. The VMI scenario was to help decrease the costs of warehousing by about $40 \%$, and the eService scenario was to help simplify the shipment process and decrease costs by about $20 \%$.

\subsection{Phase 2: Design and Evaluation of Scenarios}

\subsubsection{Pilot Partner Selection}

Woodbridge analysed the market in South America and selected three corporations with which they considered co-operation to be a viable proposition: Wheat Ind., Brewers Finest and Delta Choc. ${ }^{32}$ Walters Best and these new corporations signed a preliminary co-operation agreement. Walters Best was defined as the pilot partner and the others as partners for the continuation phase of the project when the pilot was rolled out.

\subsubsection{Process Analysis}

Woodbridge and its partners held various workshops in order to obtain a clear picture of how the benefits could be shared within the collaboration scenario, i.e. the

${ }^{31}$ VMI is a supply chain strategy that helps a company to collaborate with its customers to gather individual demand forecasts and synchronizes forecasts with local production plans to achieve greater flexibility in the planning and manufacturing process.

${ }^{32}$ Wheat, Ind. produces cereal products, Brewers Finest is a large brewery and Delta Choc. produces various sweets. 
win-win situation. The overall co-operation principles, performance and cooperation goals were also defined. This included, for example, how to deal with conflicts, trust building and management, behavior in relation to competitors and collaboration processes. Finally, the main performance indicators for the scenario were fixed (see Table 2).

\begin{tabular}{|l|l|l|l|}
\hline Scenario & Process & Metric & As-is Value \\
\hline VMI & Make-to-Stock & Capacity utilisation & $40 \%$ \\
\hline VMI & Make-to-Stock & Unit cost & US\$ 1m \\
\hline eService & Deliver Stocked Products & Order fulfilment cycle time & 5 days \\
\hline eService & Plan Deliver & $\begin{array}{l}\text { Order management cost per } \\
\text { ton of plastic }\end{array}$ & US,000 \\
\hline
\end{tabular}

Table2: Metrics of Scenarios at Start of Project

The to-be business architecture shows the pilot project and the continuation partners, all warehouses, distribution centers, plants, etc. (see Figure 10).

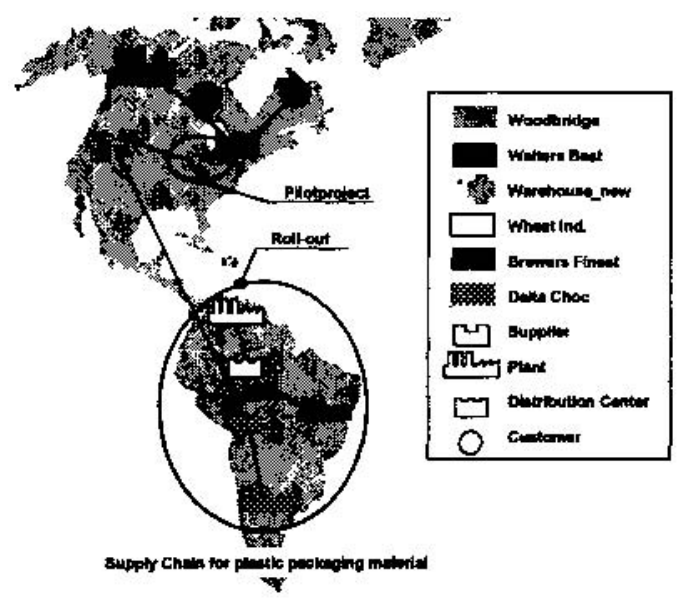

Figure10. To-Be Business Architecture

While the responsibilities of the various customer services remained unchanged, Warehouse V and the new Warehouse B are now managed by Woodbridge. It is responsible for product availabilities and stock level optimisation. Transport has been completely outsourced to a new partner, eLogistics (see Figure 11). 


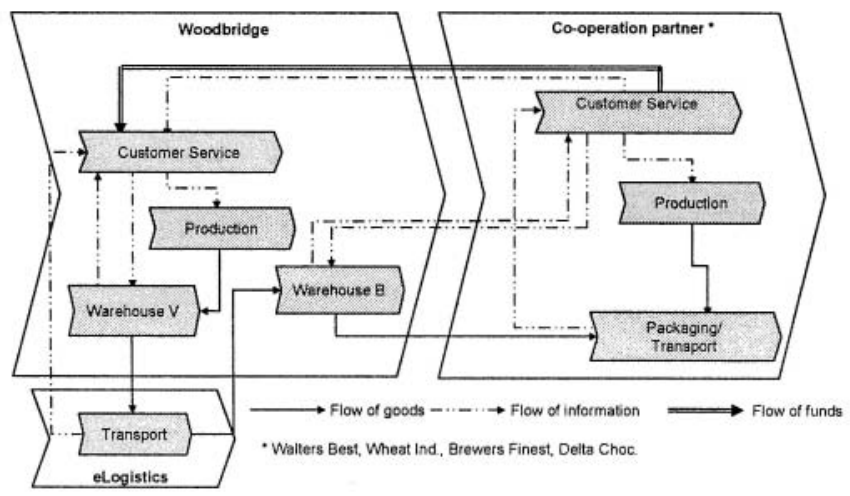

Figure 11. The To-Be Process Architecture - Macro

These facts are again depicted in Figure 12 'Source stocked products' now belongs to Woodbridge and 'Plan deliver' and 'Deliver stocked products' to eLogistics. For the interaction with eLogistics an EC solution was established to facilitate requests for required capacities, availabilities and status information by developing two new processes: 'Inform MTO service' and 'Contract MTO service'.

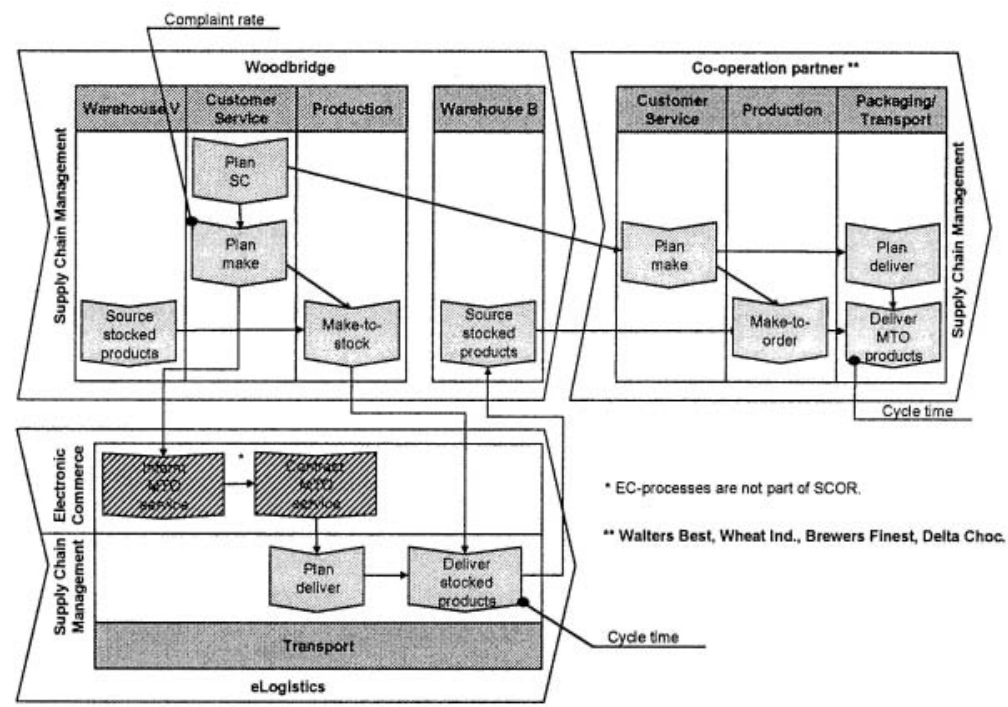

Figure12. To-Be Process Architecture - Micro

\subsubsection{Design of IS Architecture}

To manage the new warehouses and continuous forecasting, Woodbridge implemented an APS that has various interfaces to the core ERP systems of Woodbridge and partners. On the other hand, Woodbridge uses an electronic catalogue system from eLogistics that shows availabilities and conditions of 
transporters (see Figure 13) as well as the status of parcels to be delivered to partners and to Woodbridge itself via the Internet.

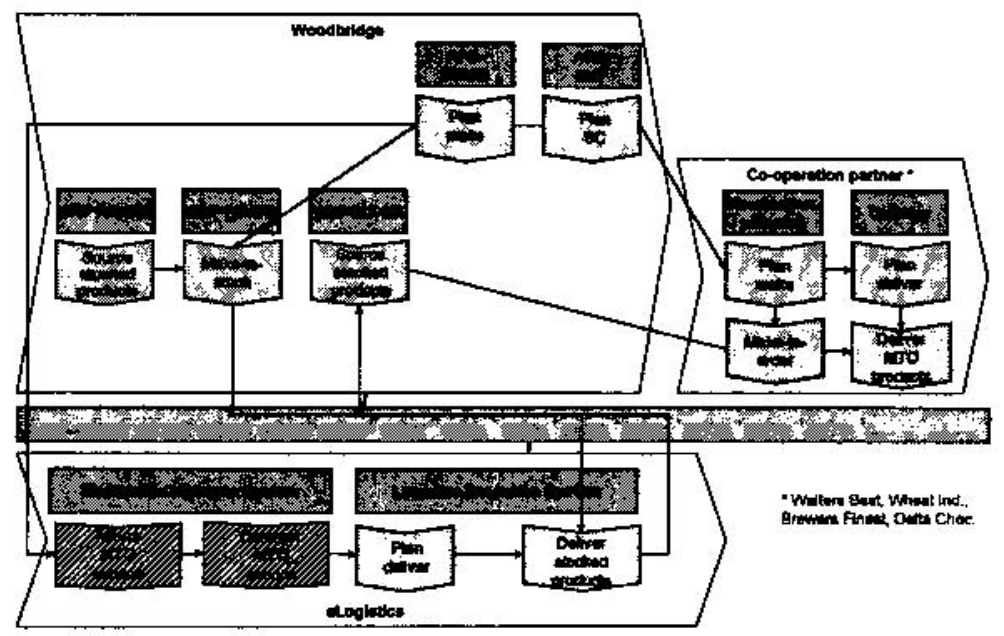

Figure13. To-Be IS Architecture

\subsection{Phase 4: Continuation}

At the end of the project a final evaluation of the main goals was conducted. Table 3 shows one result document out of technique ' 4.1 Establish Operational Cooperation Management'. Final, the project led to significant reductions in all core metrics.

\begin{tabular}{|l|l|l|l|}
\hline Scenario & Process & Metric & To-be Value \\
\hline VMI & Make-to-Stock & Capacity utilisation & $85 \%$ \\
\hline VMI & Make-to-Stock & Unit cost & US\$ 560,000 \\
\hline eService & Deliver Stocked Products & Order fulfilment cycle time & 1.5 days \\
\hline eService & Plan Deliver & $\begin{array}{l}\text { Order management cost per } \\
\text { ton of plastic }\end{array}$ & US\$ 8.500 \\
\hline
\end{tabular}

Table3: Metrics of Scenarios at End of Project

\section{CONCLUSION}

Due to their specific characteristics, Business Networking or co-operation projects require additional steps and competencies in project work and procedure. Although a variety of methods are available, these methods present significant shortcomings since they either focus only on strategic aspects, do not include 
knowledge of networking processes, or else provide only a low level of formalisation.

The advantages of a method for Business Networking are that it:

- provides an integrative framework that includes all activities relevant to analysing, designing, planning/implementing and continuing Business Networking projects. It offers a structured path from (strategic) analysis and conceptualisation to implementation. Strengths of existing methods can be integrated.

- facilitates inter-organisational project management by providing a common procedure model, using understandable techniques and result documents as well as role descriptions. This helps to structure a shared project plan, to determine which tasks have to be performed and to decide who should be involved at which stage of the project. Problems arising from different corporate cultures, languages and systems can be avoided.

- addresses critical success factors relevant to Business Networking. The success of Business Networking projects is often determined by non-technical, i.e. organisational and political factors. Examples are creating win-win situations, homogenisation of master data and the like.

- supports knowledge management by transferring knowledge relating to prior and ongoing projects. It includes success factors and best practices as well as critical configuration and implementation know-how. Besides helping to provide direct benefits for project management, the method improves employee training. In doing so, it increases the flexibility and responsiveness of an organisation to cope with future networking challenges.

The information age presents a variety of challenges to management. The implications and opportunities are dynamic and the method for Business Networking represents a solid foundation for tackling these challenges in a systematic way. We see two areas in which the method can be extended:

- Interaction with knowledge management. The increasing volume of electronic transactions handled via Business Networking systems presents an important source for extracting information about customers. The integration of transaction-oriented and relationship-oriented Business Networking systems will provide new perspectives for creating tailored and efficient customer service.

- Development of eServices. Electronic services will be an important part of Business Networking in the future. How eServices can be developed or how they can be integrated at business, process and IS level are questions to be addressed in further development of the method.

- Electronic marketplaces. In comparison with long-term supply chain projects, co-operation with business partners by means of electronic marketplaces is frequently of a short-term nature. Extending the method to include techniques which also cover systems of this kind represents another direction in which the method might be developed. 
5. REFERENCE

14. Kalakota, R., and Robinson, M. e-Business: Roadmap for Success. Reading (MA) etc.: Addison Wesley Longman, 1999.

15. Österle, H. "Enterprise in the Information Age." In Business Networking: Shaping Enterprise Relationships on the Internet, ed. Hubert Österle, Elgar Fleisch, and Rainer Alt, 2. ed., 17-54. Berlin etc.: Springer, 2001.

16. Fleisch, E. Das Netzwerkunternehmen - Strategien und Prozesse zur Steigerung der Wettbewerbsfähigkeit in der "Networked Economy". Heidelberg: Springer, 2001.

17. Wigand, R. T., Picot, A., and Reichwald, R. Information, Organization and Management. Chichester: Wiley \& Sons, 1997.

18. Alt, R., Puschmann, T., and Reichmayr, C. "Strategien zum Business Networking." HMD - Praxis der Wirtschaftsinformatik, Volume 38, Number 217, 2001, pp. 43-55.

19. Puschmann, T., and Ah, R. "Enterprise Application: The Case of the Robert Bosch Group." A paper delivered at the Thirty-Fourth Annual Hawaii International Conference on System Sciences, Hawaii, 2001.

20. Gutzwiller, T. A. Das CC RIM-Referenzmodell für den Entwurf von betrieblichen, transaktionsorientierten Informationssystemen. Heidelberg: Physica, 1994.

21. Doz, Y. L., and Hamel, G. Alliance Advantage: The Art of Creating Value through Partnering. Boston: Harvard Business School Press, 1998.

22. Gomez-Casseres, B. The Alliance Revolution - The New Shape of Business Rivalry. Cambridge: Harvard University Press, 1996.

23. Håkansson, H., and Snehota, I. Developing Relationships in Business Networks. London etc.: Routledge, 1995.

24. Chisholm, R. F. Developing Network Organizations: Learning from Practice and Theory. Bonn etc.: Addison Wesley Longman, 1998.

25. Sydow, J. Strategische Netzwerke: Evolution und Organisation. Wiesbaden: Gabler, 1992.

26. Davenport, T. H. Process Innovation: Reengineering Work Through Information Technology. Boston: Harvard Business School Press, 1993.

27. Hess, T., and Brecht, L. State of the Art des Business Process Redesign. Wiesbaden: Gabler, 1995.

28. Bowersox, D. J., and Closs, D. J. Logistical Management: The Integrated Supply Chain Process. New York etc.: McGraw-Hill, 1996.

29. Christopher, M. Logistics and Supply Chain Management: Strategies for Reducing Costs and Improving Services. 2 ed. London: Financial Times/Pitman Publishing, 1998.

30. SAP. "Global ASAP, Version 1.0, CD-ROM." , Juni 1999. 1999.

31. IMG, A. PROMET SSW: Method for the Implementation of Standard Application Software Packages, Release 3.0. St. Gallen: IMG AG, 1998b.

32. i2. Rhythm - An Overview. Irving: i2 Technologies, 1997a.

33. Syncra. QuickWin: Guide to Trading Partner Collaboration.: Syncra Software, Inc., 1998.

34. Heym, M., and Österle, H. "Computer-aided Methodology Engineering." Information and Software Technology, Volume 35, Number 6, 1993, pp. 345-354.

35. IMG. PROMET BPR, Methodenhandbuch für den Entwurf von Geschäftsprozessen, Version 2.0. St. Gallen: Information Management Group/Institut für Wirtschaftsinformatik Universität St. Gallen, 1997b.

36. Scheer, A.-W. ARIS - Business Process Frameworks. Berlin etc.: Springer, 1995. 
37. Österle, H. Business in the Information Age: Heading for New Processes. Berlin etc.: Springer, 1995.

38. Brenner, C. Techniken und Metamodell des Business Engineering. St. Gallen: Institute for Information Management, University of St. Gallen, 1995. Doctoral Thesis.

39. Heinen, E. Industriebetriebslehre: Entscheidungen im Industriebetrieb. 9 ed. Wiesbaden: Gabler, 1991. 